\title{
Micro Level Determinants of Private Investment Performance: Focus in Soro Woreda in Hadiya Zone; Southern Ethiopia
}

\author{
Birhanu Hankamo Kintamo (MSc.) \\ Department of Economics, Wolaita Sodo University, Ethiopia
}

\begin{abstract}
The study set out to make empirical analysis on factors influencing private investment performance in Soro Woreda. In doing that, the study collected primary data from investors Registered Private Investment in Soro Woreda in year 2018 through administering a questionnaire to respondents. The study used both qualitative and quantitative approaches and covered domestic private investment. The study reveals that the variables: political factors, location factors and market factors were significant with positive correlation with private investment in Soro Woreda. Hence, have predictive powers over private investment in Soro Woreda. The results show that investment facilitation services have positive and significant predictive power as a factor to attract more investment to Soro Woreda. For example size of the market, government law and regulation, incentive given from town investment facilities provided in the Soro Woreda. This is portrayed by the probability of $0.034,0.085,0.054$ and 0.007 which is significant at 5\%,10\% and 1 per cent level respectively. The rest of the variables like political factors, government rules and regulations, raw material availability, political stability and however, are not significant and hence have no predictive power as attraction of investment to Soro Woreda.
\end{abstract}

Keywords: Investment, micro-level, private investment, logistic regression.

DOI: $10.7176 / \mathrm{JESD} / 10-11-07$

Publication date:June $30^{\text {th }} 2019$

\section{Introduction}

\subsection{Background of the Study}

Investment is an instrument which has a great role in development of an economy especially for less developed countries like Ethiopia. This is because of the importance of investment to bring employment opportunities, effectiveness of domestic resource, large production, specialization, which do not fulfill in developing countries (Birhanu and Befekadu, 2003).

Factors influencing private investments differ worldwide from one country to the other. However the importance attached to private investment is common across the universe. Thus, over recent years, the private investment has been labeled the engine of economic growth in a country. Every country prefers to have as much private investment as possible in order to enhance economic growth and development. This means that, private investment is one of the most important sources of economic growth and employment. It supplements the government investment efforts in enhancing proper functioning of the economy (Imtiaz, 2008).

Considering the challenges and opportunities that are learned from the first GTP implementation and by taking the global economic condition into account, the second growth and transformation plan (GTP II) is formulated. The prime objective of the second growth and transformation plan is to attain an annual average GDP growth rate of 11 percent within stable macroeconomic environment, and to achieve rapid industrialization and structural transformation (IGE, 2015). Unlike in the first GTP, in the second growth and transformation plan the government gives attention for quality investment in all sectors of the economy. As a result, ensuring quality, productivity, competitiveness and efficient utilization of existing capacity is the major strategic direction of the plan. And also, countries have been keen in positioning themselves properly to stand an increasing competitive market for a limited supply of investment resources. So then, slowdown in private investment is translated in to a slowdown in economic growth that leads to decrease in revenue. Thus Ethiopian government should have recognized the role to facilitate the private sector to actively and effectively invest in productive and commercial activities in order to accelerate economic growth and development. Against this background, this study assesses the micro level determinant of private investment in Soro Woreda, Hadiya Zone, South Ethiopia.

\subsection{Statement of the Problems}

Private investment plays a great role in country's development especially in developing countries whose capital is scarce and their government lack enough capacity to cover all constraints and bring economic change for development .thus, if private investment (sectors) involved in investment, the growth domestic product (GDP) of the country will increase (Imtiaz, 2008).

Although a number of incentives and support packages are designed to encourage the participation of the private sector in the growth and development of the country during GTP II implementation period, there are a number of challenges that hindered the private sector to contribute in the development process of the country (NPC, 2016). During the implementation of GTP it has been noted that limited role is envisaged for the private sector 
and the financing needs for the public sector crowd out private sector credit on the domestic side (WB, 2015). As such, the private sector was not able to play significant role and the bulk of the private sector contribution is in the services and informal sectors. According to World Bank (2015) the top five problematic factors for doing business in Ethiopia are: inefficient government bureaucracy, foreign currency regulations, and access to finance, corruption, and inadequate supply of infrastructure.

A vast number of theoretical literatures have looked at the determinants of investment. However, these theories fail to explain decision to invest by considering other factors in the same model. Similarly, several empirical studies related to the determinants of private investment have been conducted. For example, Ambaye, G.G., Berhanu, T. \& Abera, G. 2014 demonstrated that output has indeed been one of the main determinants of private investment and Zeufack (1997) explains this finding by the non-homogeneity of institutional constraints perceived and faced by the two categories of firms due to information asymmetries. One should therefore pay attention to this difference in reaction and explicitly take it into account while designing policies aimed at promoting private investment.

Though most of these studies follow a macroeconomic approach and make use of secondary data. Few studies which tried to incorporate other variables apart from macroeconomic variable have only dwelt on determinants of FDIs. On the other hand the uniqueness of this study is that, it encompasses wide range of factors influencing private investment decision instead of dwelling on capital concerns only as in many other literatures and theories of investment. Moreover, various studies and models elsewhere explain factors influencing private investment decisions in a particular sector with factors that do not suit environment, hence leaving various variables which presumably can influence private investment decision. Therefore, there is lack of survey studies aimed at presenting the current situation on factors influencing private investment decision in study area generally. Therefore study will try to measure the strength of level of influence on private investment decision in Soro Woreda on various variables. So this study is outstanding in the sense that, it encompasses opinions from different angles to identify the significance of specific factors in explaining the private investment activity and so, the study on determinants of private investment performance was not yet done in the study areas.

\subsection{Objective of the Study}

The general objective of the study is, to assess determinants of private investment performance in Soro Woreda. Specifically; to examine microeconomic factors affecting private investment performance and to explore other option to improve private investment statuses in Soro Woreda.

\section{Research Methodology}

\subsection{Research Design}

The research design of this study was descriptive survey method, which focuses on investigating the current status of Micro Level private investors in Soro Woreda.

\subsection{Participant of the Study}

The target population estimated in this stud was micro level private investors in Soro Woreda.

\subsection{Sampling Techniques}

A simple random sampling technique was used in this study to collect primary data. Considering the objective of the study and representativeness of the sample, all 122 micro level investors employed.

\subsection{Tools of Data Collection}

Source of data to this study were both primary and secondary data. Primary data collected using a structured questionnaire with the help of trained enumerators. The questionnaire includes personal information, socio demographic profile of household head, and outcome variables income of households.

\subsection{Data Analysis Methods}

The study uses both qualitative and quantitative approaches to analyze the collected data. The data collected from different sources is analyzed using the STATA13 software. The descriptive statistics used in this study include mean, standard deviation, percentages and frequency of occurrence, Chi-square and econometric analysis was intended to use. It was conducted based on the data obtained from the sample of the research target collected through questionnaire. The Logit model used to identify factors influencing the willingness to invest. The coefficients of the Logit model can be disaggregated to determine the effect of a change in one variable on changes in the probability to invest and in the expected intensity of investment capital use.

\subsubsection{Model Specification}

Logistic regression, also called a Logit model, was used to model factors that affects firms decision to invest in Soro Woreda since decision to invest is a dichotomous outcome variable. In this model; the log odds of the outcome 
is modelled as a linear combination of the predictor variables. Given that the research was interested in the factors that influence whether a firm decides to invest in Soro Woreda or not; the outcome (response) variable is binary $(0 / 1) ; 1$ whether a firm invests in Soro Woreda and 0 otherwise. The predictor variables of interest in this model are political factors, government laws and regulations, location factors, market factors, and financial and macroeconomic factors. Consequently, empirical model assumes that private investment is linear to: output, political factors, government laws and regulations factors, location factors, market factors and financial factors. The omission of the constant term could bias the result substantially. Thus, analysis tested for the significance of the factors (Political stability, government laws and regulations factors, location factors, market factors, microeconomic and financial factors) which presumably influence private investment activity in Soro Woreda.

Based on the above the relationship is assumed to be linear and we used survey data set all 122 firms registered by Soro Woreda Investment office in 2018. Specifically, the basic logistic model formula employed to estimate private investment activity in Bombe Woreda is:

$\mathrm{PI}=\mathrm{Z}=\beta 0+\beta 1 \mathrm{x} 1+\beta 2 \mathrm{x} 2+\beta 3 \mathrm{x} 3+\beta 4 \mathrm{x} 4+\beta 5 \mathrm{x} 5+\beta 6 \mathrm{x} 6+\beta 7 \mathrm{x} 7+\beta 8 \mathrm{x} 8+\beta 9 \mathrm{x} 9+\beta 10 \mathrm{x} 10+$ $\beta 11 \times 11+\beta 12 \times 12+\mu \mathrm{i}$.

The variable $\mathrm{Z}$ the dependent variable is the measure of the total contribution to private investment of all private investment factors (predictor variables) used in the model. Here $\beta 0$ is the intercept (constant), and $\beta 1$ through $\beta 2 \ldots \ldots \ldots 12$ are the regression coefficients of the predictor variablesx $1, x 2, x 3, x 4$ and .. $x 12$ respectively. The computed pvalue of $f(z)$ is the probability of a particular outcome in the presence of the risk factors with the value range of 0 to 1 . If $\mathrm{P}$ is a probability the, $\frac{\mathrm{P}}{1-\mathrm{P}}$ is the corresponding odds

$\mathrm{Yi}=\mathrm{xi} \mathrm{i}+\mu \mathrm{i}$

Where,

Yi Denotes the dichotomous qualitative variable; xi Denote the vector of predictor variables;

$\beta$ Denotes vector of parameters; $\mu$ i denotes the residuals (errors)

$\mathrm{PI}=$ Private investment (the dependent variable);

$\mathrm{x} 1=$ Interest rate; $\mathrm{x} 2=$ Investment types

x3 =Government laws and regulatory factors; $\mathrm{x} 4=$ Location factors;

x5 =Market factors; $\mathrm{x} 6=$ Institutional credit

$\mathrm{X} 7=$ Level of education, $\mathrm{X} 8=$ Access to investment Information

$\mathrm{X} 9=$ tax rate perception, $\quad \mathrm{X} 10=$ Information access

$\mathrm{X} 11=$ investment incentive,$\quad \mathrm{X} 12=$ Political factors

The binary variable (presence or absence) of the predictor variable, expression is defined as follow:

yi $=\left\{\begin{array}{l}1 \text { if yi }>z \\ 0 \text { if yi } \leq z\end{array}\right.$

The maximum-likelihood estimator (ML) of $\mathrm{B}$ is given by maximizing the following log-likelihood function by $L(y, x \beta)=\prod_{i=1}^{N}\left(\frac{1}{1+\exp x i \beta i}\right)^{1-y i}\left(\frac{\exp -x i \beta i}{1+\exp x i \beta i}\right)^{y i}$

\section{Data Analysis and Interpretation}

\subsection{Descriptive statistics result}

3.1.1. Occupation level of investors

Table 3.1: Respondents by willingness to invest in related sectors of economies

\begin{tabular}{|c|c|c|c|c|}
\hline \multirow[t]{2}{*}{ Sector of economy } & \multicolumn{2}{|c|}{ Willingness to invest } & \multirow[t]{2}{*}{ Total } & \multirow[t]{2}{*}{ chai-square } \\
\hline & $\mathrm{O}(\mathrm{No})$ & 1 (Yes) & & \\
\hline Other & $11(13.4 \%)$ & $7(16.3 \%)$ & $18(14.4 \%)$ & \\
\hline Mining & $8(9.8 \%)$ & $6(14 \%)$ & $14(11.2 \%)$ & $2.312 * *$ \\
\hline Manufacturing & $34(41.5 \%)$ & $17(39.5 \%)$ & $51(40.8 \%)$ & $3.412 * *$ \\
\hline Agriculture & $29(35.4 \%)$ & $13(30.2 \%)$ & $42(33.6 \%)$ & $2.012 * *$ \\
\hline Total & 81 & 41 & 122 & \\
\hline
\end{tabular}

Source: survey result, $2018 * *$ Significant at 5\% level

As shown above (table: 3.1 ) private investors in Soro Woreda are engaged in various sectors of economy. Those activities are divided in to 4 sectors, agricultural, manufacturing, mining, and other sectors which account $30.2 \%, 39.5 \%, 14 \%$ and $16.3 \%$ from the total respondent respectively. Type of sector the respondents engaged has significant effect on investment. The result shows that With respect to the willingness to invest, majority of investors are engaged in agricultural sectors next to manufacturing sectors.

\subsubsection{Factors Influencing Private Investment performance}

As demonstrated in table 3.2 below; almost 65.83 percent of the willing and 48.8 percent of the non-willing sample respondents have access to credit and 31.3 percent of the willing and 49.06 percent of the non-willing investors 
suffered the same problem of having access to credit. The Chi-square value indicates that the difference between the two sample groups with regard to access to credit was statistically significant at less than 1 percent level. On the other hand, this result indicated that shortage of credit is a constraint to investment activities. As interest rate is an important determining factor for any type of private investment decision, the sample respondents were asked to judge the level of interest rate.

The Chi-square value indicated that this variable was insignificant. The result also showed that both the willing and the non-willing groups responded that rate of interest was medium i.e. it is neither high nor low, which constitute larger proportion, 38.32 and $37.42 \%$, respectively. Whereas $21.66 \%$ and $26.66 \%$ of the total respondents thought that the interest rates were very high and high, respectively. While the rest $14.92 \%$ of the total sample respondents said it was low. This implies that interest rate was not the main factor to make decision on investment. As the survey result indicates tax rate is an important determining factor for any type of private investment performance, the sample respondents were asked to judge the level of interest rate. The Chi-square value indicated that this variable was insignificant. The result also showed that both the willing and the non-willing groups responded that rate of tax was medium i.e. it is neither high nor low, which constitute larger proportion, 36.82 and $39.40 \%$, respectively.

Whereas $24.38 \%$ and $17.99 \%$ of the total respondents thought that the tax rates were very high and high, respectively. While the rest $15.56 \%$ of the total sample respondents said it was low. This implies that tax rate affects the decision of firms. Another very important factor impacting on investment decision making is the existence of political instability. The survey result showed that there is no big difference among the two sample groups regarding political instability. The result also showed that 27.8 percent of the willing sample respondents reported that there was fear of political instability in the study area and similarly 44.3 percent of the non-willing groups also agreed to the same idea.

Table 3.2: financial credit access, tax rate perception and interest rate perception of sample private investors

\begin{tabular}{|c|c|c|c|c|c|c|c|}
\hline Attributes & \multicolumn{2}{|c|}{ Willing } & \multicolumn{2}{|c|}{ Non-willing } & Cha-square & \multicolumn{2}{|c|}{ Total } \\
\hline \multicolumn{8}{|l|}{ Access to credit } \\
\hline Have access & 33 & 65.85 & 39 & 48.8 & $4.2911 * * *$ & 72 & 53.32 \\
\hline Have no access & 20 & 31.34 & 30 & 49.05 & & 50 & 46.63 \\
\hline \multicolumn{8}{|l|}{ Tax rate } \\
\hline Very high & 12 & 24.38 & 14 & 17.99 & \multirow[t]{4}{*}{$1.892 * *$} & 26 & 21.66 \\
\hline Medium & 19 & 29.45 & 15 & 23.23 & & 32 & 26.66 \\
\hline High & 21 & 36.82 & 23 & 39.40 & & 44 & 37.87 \\
\hline Low & 7 & 14.82 & 11 & 15.82 & & 18 & 15.56 \\
\hline \multicolumn{8}{|l|}{ Interest rate } \\
\hline Very high & 18 & 25.37 & 8 & 16.98 & 1.781 & 26 & 21.66 \\
\hline High & 18 & 28.37 & 16 & 25.2 & & 32 & 26.66 \\
\hline Medium & 24 & 38.32 & 20 & 37.42 & & 41 & 37.87 \\
\hline
\end{tabular}

Also the study showed that 68.67 percent of the willing respondents have access to investment information for investment activities while 34.32 percent of the non-willing respondents reported that they didn't have access to information for investment. The Chi-square value indicated that there is a difference between the two sample groups with regard to access to information for investment, which was found to be statistically significant at 5 percent level. The result showed that almost $62.05 \%$ of the willing and $38.56 \%$ of the non-willing sample respondents have access to market. The Chi-square value indicated that this variable was significant at $1 \%$ level. According to this study, most investors who had access to market were willing to invest whereas those who didn't have access to market weren't interested in making investment. Thus, access to market has a key role in making investment decision.

As the survey result, almost $54.9 \%$ of the willing and 39.18 percent of the non-willing respondents have reported that they have access to location. In other words, on average, the proportion of access to location for willing groups was larger than that of non-willing groups. This implies that if there is adequate location, investors are motivated to invest. The Chi-square value also indicated that there is a significant difference between the two sample units at 5 percent level. Moreover, more than 50 percent of the willing and 51percent of the non-willing groups of the respondents complained that the physical location problem in Soro Woreda.

\subsection{Econometric Results}

\subsubsection{Multicollinearity and heteroscedasticity tests}

Prior to running the Logit model, the hypothesized explanatory variables were checked for the existence of multi collinearity and heteroscedasticity. Consequently, researcher may have little confidence in any policy prescriptions 
on these estimates. It is thus, important to test for the presence of collinearity between variables before running a regression. The VIF values of the variables in the model as shown in are much more less than the critical values showing that there is no problem of co-linearity. Likewise, contingency coefficients were used to check for association among the discrete variables. Since all the VIF values are less than 10 this proves that there was no serious problem of Multicollinearity among the continuous explanatory variables. Consequently, all of the continuous explanatory variables were used in the estimation of the specified mode. Thus it can be concluded that there was no problem of strong association among the discrete variables as the respective coefficients were very low.

\subsubsection{Discussion of the econometric results}

The model results show that the coefficients of results of 8 of the 12 explanatory variables that were hypothesized to affect potential investors' decision to invest in the investment activities were statistically significant. It is worth noting that all of these eight explanatory variables that were found to significantly affect the level of investment in the hypothesized signs.

Among the eight variables that were found to significantly affect the level of investment in the investment activity, the coefficients of the sample investor's level of education, access to credit, location access, investment information, and market access were positive, implying that these variables had a significant investmentenhancing impact. Whereas the coefficients of perception of the level of interest rate, political instability, and tax rate had negative signs, implying that these variables had a significant investment deterring impact.

A p-value of less than 5\% was declared as significant statistical relationship between dependent (investment) and independent variables (willingness to invest). All variables associated with investment in binary logistic regression with value of $(\mathrm{P}<0.05), \mathrm{P}<0.01$ and $\mathrm{P}<0.1$.

As depicted from table 3.3 below totals of 12 explanatory variables were considered in the economic model, out of these eight of the variables were found to be significant at $5 \%$ and $10 \%$ significant level, while the remaining seven were not significant in explaining the variations in the dependent variable. Year of establishment, sector types, political factors, investment facilities and investment incentives were found to be statistically significant. However, the remaining nine explanatory variables namely, Age, sex, and educational level, position of respondents, owner of investment, location factors, and market factor had no significant effect on the probability of being defaulter (Table3.3).

Table 3.3: The estimates of binary logistic model and the effects of explanatory Variables on the investment performance on selected variables

\begin{tabular}{l|l|l|l|l|l|l} 
Variables & Coef. & Std. Err. & $\mathrm{T}$ & $\mathrm{P}>\mathrm{t}$ & {$[95 \%$ Conf. } & Interval $]$ \\
\hline Edlvl & -.0129926 & .0567681 & -0.23 & 0.819 & -.1255287 & .0995435 \\
\hline Noeplye & .0036014 & .0220161 & 0.16 & $0.0870^{*}$ & -.0400429 & .0472456 \\
\hline posrespo & .0590859 & .0695859 & 0.85 & 0.398 & -.0788599 & .1970318 \\
\hline Sectyp & -.0880574 & .0527103 & -1.67 & $0.098^{*}$ & -.1925494 & .0164346 \\
\hline Stusorg & .0396573 & .1018841 & 0.39 & $0.0698^{*}$ & -.1623161 & .2416307 \\
\hline Dpfinvst & .2021239 & .0916097 & 2.21 & $0.029^{* *}$ & .0205182 & .3837295 \\
\hline dgvlregfivst & -.1400344 & .1133879 & -1.24 & $0.0220^{* *}$ & -.3648128 & .084744 \\
\hline dlocfinvst & -.0099633 & .1021406 & -0.10 & 0.922 & -.212445 & .1925184 \\
\hline dmrkfinvst & .163047 & .1010938 & 1.61 & $0.0110^{* *}$ & -.0373595 & .3634536 \\
\hline arstscmprgspro & .2287497 & .1145595 & 2.00 & $0.048^{* *}$ & .0016489 & .4558505 \\
\hline arstsivtfacsrv & .1289603 & .1101483 & 1.17 & 0.244 & -.0893958 & .3473165 \\
\hline Arstsinctsrv & .2020889 & .0910035 & 2.22 & $0.028^{* *}$ & .021685 & .3824928 \\
\hline cons & 47.88655 & 23.16407 & 2.07 & 0.041 & 1.966492 & 93.80662
\end{tabular}

Source own data computation, 2018

$* *$, and * indicate significance at $5 \%$ and $10 \%$ probability level, respectively

\subsubsection{The explanation from interview}

According to investment office of Soro woreda currently private investment has facing internal and external problems. Some of internal problems are:- shortage of supervision and monitoring ,Poor documentation, insufficient working area ,shortage of loan able funds for further expansion and high turnover of employees' to other organizations. In addition to this some external problems like; government collateral for job creating opportunity, interference of third party in the decision of investment location. As of one of the officer opinion, "one of the factors which affect investment performance is lack of motivation of workers. I am working in this office more than three years in my stay time; there is no salary improvement as well as scholarship chance. Even if this institution do not apply BSC, so our future is not good. So we are not volunteers to supervise and provide service according to standards, no measurement at all. In addition to this no training is given by the institutions and work load on employee. During my supervision time some investors believe investment land as gift of government, has no plan to re-invest and need incentives without interest rate. Many investors stated that there is 
no that much follow up and supervision to continue our activity from government officials. Also the tax rate most of the time is not based on our capital, i.e. even our capital is not increased that much (as the result of lack of sufficient information) government revenue officials simply levy the tax.

\section{Conclusion and Recommendation}

\subsection{Conclusion}

Based on the analysis result, the following conclusions were made on socio demographic characteristic of investor's willingness and institutional related factors as follows: - In this study, both descriptive and econometric analyses were used for analytical purpose. The analysis has shown that access to credit, level of education, access to location, access to market, interest rate perception, investment information, tax rate and political instability were among significant variables affecting probability of willingness and intensity of capital. Also the regression analysis reveals that from the given explanatory variables; access to credit, access to location, education level of investor, investment information and market access are positive and significant determinants of investment decision which increases the intensity of capital. Also interest rate perception at high rate and political instability and high tax perception are negative and insignificant determinants of probability of performance of investor. Governance can motivate investors to increase their willingness to invest by providing them to information about investment. Moreover to this, as it mentioned from interviewer there is a need for a continuous supervision on firms' performance in investment condition like investment land holding, service providing and incentive giving. Furthermore, good climate of politics and access to market can motivate the firm to invest in Soro Woreda.

\subsection{Recommendations}

Based on the result of the study, the following recommendation are suggested to be considered for future intervention strategies by zonal government and Soro woreda administration which are aimed for promotion of private investment in the area are:-

$\checkmark$ To motivate firms to invest in specifically in Soro woreda, investment department should provide good environment to investors with regard to facilities service and incentives.

$\checkmark$ The researcher recommends that government should provide training guidelines for the firms before they start their operation.

$\checkmark$ Government should minimize the level of tax rate based on the level of capital of private investors.

$\checkmark \quad$ Further study should be needed in the study area for more investigation on determinants of private investment decision and the determinants of investment purpose in investment performance is recommended to validate the consistency of my results.

\section{REFERENCES}

Akpalu W. (1997). Determinants of private investment in Ghana.AnMsc thesis presented to the school of graduate of Addis Ababa

Alemayehu Geda and Haile Kibret (2007). Aggregate Saving Behavior In Africa: A Review of the Theory and the Existing Evidence with New Empirical Results.

Ambaye G.G., BerhanuT. \& Abera.G. (2014). 'Modeling the determinants of domestic private investment in Ethiopia.' Agris on-line papers in Economics and Informatics, V (4), 13-23.

AnyanwuJ.C.(1998). 'An econometric investigation of the determinants of foreign investment in Nigerian economic society' In Rekindling investment for economic development in Nigeria, Ibadan: Nigerian Economic Society: 219-41.

Anyanwu J.C. (2006). 'Promoting of investment in Africa,' African Development Review, 18(1), $42-71$.

Asante Y. (2000). Determinants of private investment behavior. Nairobi: AERC Research Paper No. 100.

Asmelash B. (2007). Opportunities and service delivery of investment in Tigray, Msc Balassa, B., 1988. Public Finance and Economic Development PRE: Working Paper 31, World Bank, Office of the Vice President for Development Economics, Washington D.C

Blejer M. \&Khan M.S.(2004). Government policy and private investment in developing countries. IMF working papers, Washington.

Brehanu, N. \&Befikadu U, d. (2003/2004).annual report on Ethiopia economy.vol.3.ethiopia economic association press, Addis abeba, Ethiopia.

Collier, P. and J.W. Gunning (1999). Explaining African Economic Performance, Journal of Economic Literature 37: 64-111.

CSA (Central Statistical Authority) (2005). Statistical Abstract. Addis Ababa, Ethiopia

EIC (Ethiopian Investment Commission), 2004. Statistics on Investment in Ethiopia No. 6. Addis Ababa, Ethiopia.

Genenew M. (1999) analysis of determinants of household's willingness to pay and demand for improved water service: a cotangent valuation study in Harer town Ethiopia. MSc thesis presented to the school of graduate studies of Addis- Ababa University. 
Getachew Mekonnen, 1997. Determinants of Private Industrial Investment in Ethiopia. An MSc Thesis Presented to the School of Graduate Studies of Addis Ababa University.

Green, J. and D. Villanvera (1991). Private Investment in Developing Countries: an Empirical Analysis. IMF Staff Papers 38 (1): 33-58.

Gujarati D.(1995). Essentials of Econometrics. 2nd ed., Mc Graw Hill, New York, US 1999 Essentials of Econometrics. 2nd ed., Mc Graw Hill, New York, USA. 2003.

Kefay, b. (2005), Determinants of private investment at national level, MSc thesis presented to the school graduate studies of Almay University.

Keynes.j.M (1936).general theory of employment, interest and money, San Diego, Harcourt

Mbugua T. (2000). The micro and macro economy determinants of private investment in manufacturing sectors in Kenya. MSc thesis presented to the school of graduates.

Madala G.S. and Netson, F. (1997). Switching Regression Models with Exogenous and Endogenous Switching. 